\title{
CORRECTION
}

\section{Correction to: Pitfalls of clinical exome and gene panel testing: alternative transcripts}

Dale L. Bodian, Prachi Kothiyal and Natalie S. Hauser

Genetics in Medicine (2021) 23:2229; https://doi.org/10.1038/s41436-021-01131-y

Correction to: Genetics in Medicine (2019) 21, 1240-1245; https:// doi.org/10.1038/s41436-018-0319-7; published online 08 October 2018

Unfortunately, the Electronic Supplementary Material (ESM) was missing in the original online version. The ESM is available in the online version of this corrected article.

\section{ADDITIONAL INFORMATION}

Supplementary information The online version contains supplementary material available at https://doi.org/10.1038/s41436-021-01131-y.

Correspondence and requests for materials should be addressed to D.L.B.

Reprints and permission information is available at http://www.nature.com/ reprints 